\title{
Determining regional limits and sectoral constraints for water use
}

\author{
T. K. Lissner ${ }^{1,3, *}$, C. A. Sullivan ${ }^{2}$, D. E. Reusser ${ }^{1}$, and J. P. Kropp ${ }^{1,4}$ \\ ${ }^{1}$ Potsdam Institute for Climate Impact Research, P.O. Box 6012 03, 14412 Potsdam, Germany \\ ${ }^{2}$ School of Environmental Science and Management, Southern Cross University, Lismore, Australia \\ ${ }^{3}$ Geography Department, Humboldt University of Berlin, Germany \\ ${ }^{4}$ Dept. of Earth and Environmental Sciences, Potsdam University, Potsdam, Germany \\ *Invited contribution by T. K. Lissner, recipient of the Division Outstanding Young Scientists Award 2014.
}

Correspondence to: T. K. Lissner (lissner@pik-potsdam.de)

Received: 10 April 2014 - Published in Hydrol. Earth Syst. Sci. Discuss.: 12 May 2014

Revised: 25 August 2014 - Accepted: 13 September 2014 - Published: 14 October 2014

\begin{abstract}
Water is an essential input to the majority of human activities. Often, access to sufficient water resources is limited by quality and infrastructure aspects, rather than by resource availability alone, and each activity has different requirements regarding the nature of these aspects. This paper develops an integrated approach to assess the adequacy of water resources for the three major water users: the domestic, agricultural and industrial sectors. Additionally, we include environmental water requirements. We first outline the main determinants of water adequacy for each sector. Subsequently, we present an integrated approach using fuzzy logic, which allows assessing sector-specific as well as overall water adequacy. We implement the approach in two case study settings to exemplify the main features of the approach. Using results from two climate models and two forcing RCPs (representative concentration pathways), as well as population projections, we further assess the impacts of climate change in combination with population growth on the adequacy of water resources. The results provide an important step forward in determining the most relevant factors, impeding adequate access to water, which remains an important challenge in many regions of the world. The methodology allows one to directly identify the factors that are most decisive in determining the adequacy of water in each region, pointing towards the most efficient intervention points to improve conditions. Our findings underline the fact that, in addition to water volumes, water quality is a limitation for all sectors and, especially for the environmental sector, high levels of pollution are a threat to water adequacy.
\end{abstract}

\section{Introduction}

Water is a critical resource for human livelihoods and is needed for the majority of human activities. Pressure on water resources is increasing due to consumption, as well as pollution, leading to situations of water scarcity in many regions of the world. Much knowledge exists regarding the single determinants of water scarcity, making clear that water shortages are often due to quality or access, rather than due to physical water shortages (Finlayson et al., 2012; WHO/UNICEF, 2000; WWAP, 2012; Sullivan, 2002). For example, assessments of human water requirements (e.g. Falkenmark, 1997; Falkenmark and Rockström, 2004) show that the share of domestic water needs is comparably small. Nonetheless, domestic water scarcity prevails in many (developing) countries, mainly due to inadequate water quality and access (Rijsberman, 2006). Other important water users are the industrial and agricultural sectors, which each have distinct requirements regarding quantity, quality and access (Flörke et al., 2011; Falkenmark, 1997). Approaches such as the water poverty index (Sullivan, 2002) and the climate vulnerability index (Sullivan and Meigh, 2005) are important starting points in understanding and integrating the multiple aspects of water scarcity and water poverty. Today, human activities already impact water availability, and projected development pathways indicate further increases of these pressures deriving from population and economic growth (Bates et al., 2008). Additionally, climate change is expected to alter temperature and precipitation patterns (Kirtman et al., 2013; Collins et al., 2013), potentially reducing available water resources and adding to the existing situation of water scarcity. 
The majority of societal activities require water, and each sector has individual requirements. Planners and decisionmakers require tools, which allow one to view the multiple determinants in conjunction, to identify where potential limitations are most efficiently eliminated, also taking into account potential future changes. Existing approaches to assess water scarcity usually focus on single aspects of the topic; for example, on human water requirements (e.g. Falkenmark, 1997); the relationship between water use and availability (e.g. Alcamo et al., 2003); water consumption (e.g. Hoekstra and Chapagain, 2006); threats to water quality (e.g. Vörösmarty et al., 2010a); or physical scarcity and drought (for comprehensive reviews see Eriyagama et al., 2009; Brown and Matlock, 2011). Focussing on peoples' daily realities, development-oriented assessments of water access often address the aspect of water infrastructure (UN, 2012). It is also clear that sufficient water needs to be retained for functioning ecosystems (Smakhtin et al., 2004), also with regard to the long-term adequacy of human livelihood conditions. However, environmental aspects are seldom considered in assessments of human water scarcity.

This paper proposes a framework to assess the adequacy of water resources, integrating the various aspects which determine sectoral water security. Adequacy for the purpose of this analysis refers to a situation in which the quantity, quality and access to water resources is sufficient enough to meet needs, but is not necessarily abundant or ideal. While knowledge on the single important aspects for the main sectoral water users is available, an integrated approach to account for sector-specific determinants of water adequacy is missing so far. The proposed method allows one to distinguish between anthropogenic and physical causes of water scarcity; for example, due to management or infrastructural problems (economic and social water scarcity; Brown and Matlock, 2011) or due to actual resource scarcity.

To retain important information regarding the most relevant determinants and to include context-specific cause-andeffect relationships between variables, we propose the use of fuzzy logic. This method has been used in water-resource research, for example, to assess issues of water quality (Gharibi et al., 2012) or wastewater reuse potentials (Almeida et al., 2013) and could be shown as a useful tool for integrating determinants of human-environmental systems (Kropp et al., 2001; Lissner et al., 2012). By identifying the factors that are most limiting to adequate water access, the results obtained through the proposed approach can directly inform decisionmakers on how to most effectively improve access to water, extending the approaches put forward by Sullivan (2002) and Sullivan and Meigh (2005).

The objective is thus to integrate determinants of sectoral water adequacy into an overall measure of water adequacy, allowing one to identify regional limitations, as well as sectoral constraints on human water security. The analysis follows two subsequent steps. Initially, we identify criteria, which determine the adequacy of water resources for the main water-using sectors and translate the identified determinants and their relationships into a methodological framework. We then apply the framework in two countries - Indonesia and South Africa -, taking into account several scenarios of climate change to outline where climate and population change may lead to additional water stress.

The analysis steps produce an integrated overview of the adequacy of water resources, while the applied methodology allows retaining important cause-and-effect chains, which can point towards policy-relevant information. Section 2 gives an overview of the countries used as examples, outlines the analysis approach and introduces the methodological concept of the framework. We present the results in Sect. 3 and discuss them in Sect. 4, followed by some general conclusions.

\section{Methods and materials}

\subsection{Case study regions}

The two case study countries are presented in Fig. 2, showing the major cities, as well as regional population densities. Both countries currently are at a intermediate human development stage. The 2012 Human Development Index (HDI) value for Indonesia is 0.629 , with a rather strong increase from 0.422 since 1980. Like Indonesia, South Africa had a $2012 \mathrm{HDI}$ value of 0.629 , which is quite high above the average for Sub-Saharan Africa of 0.475 (UNDP, 2013). A higher development status usually results in increasing per capita water use, due to increasing water consumption across sectors. Both countries have positive growth rates in terms of population as well as economic growth, and this trend is expected to continue. Both development and increasing water use will likely increase the total water withdrawal.

Indonesia is generally quite water abundant and currently withdraws $5.6 \%$ of total renewable resources and per capita use is rather low at $531 \mathrm{~m}^{3} \mathrm{cap}^{-1} \mathrm{yr}^{-1}$. The highest share of water goes towards agricultural use (81\%), 7 and $12 \%$ are withdrawn for industrial and domestic use, respectively (FAO, 2011). Current per capita water use in South Africa is even lower at $284 \mathrm{~m}^{3} \mathrm{cap}^{-1} \mathrm{yr}^{-1}$, however about $25 \%$ of total renewable resources are currently withdrawn. This implies increasing pressure, as living standards rise and population increases. The distribution between sectors in South Africa is rather different with a relatively high fraction of domestic use at $31 \% .63 \%$ go towards agricultural production and $6 \%$ are used by industries (FAO, 2005). 


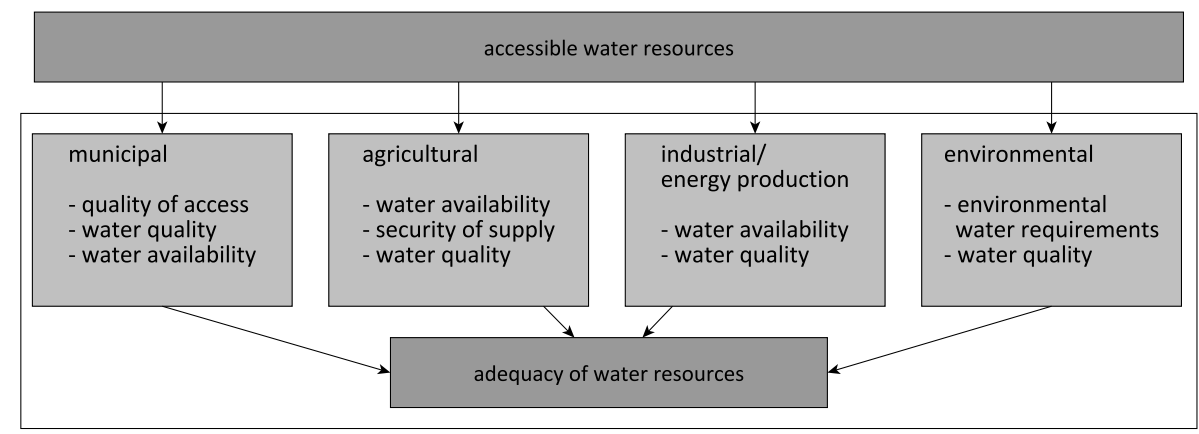

Figure 1. Conceptual overview of the determinants of sectoral water adequacy and the aggregation process.

Table 1. Overview of sectoral water needs according to different sources, all converted to $\mathrm{m}^{3} \mathrm{cap}^{-1} \mathrm{yr}^{-1}$.

\begin{tabular}{lccccr}
\hline & Chenoweth (2008) & Falkenmark (1997) & Shuval (1992) & Range & Threshold \\
\hline Municipal & 30.6 & 36 & 100 & $30.6-100$ & $30-100$ \\
Industrial & 12.6 & $36-432$ & - & $12.6-432$ & $10-400$ \\
Agricultural & & $504-1584$ & 25 & $25-1584$ & $500-1500$ \\
\hline Cumulative & & & & $540-2000$ \\
\hline
\end{tabular}

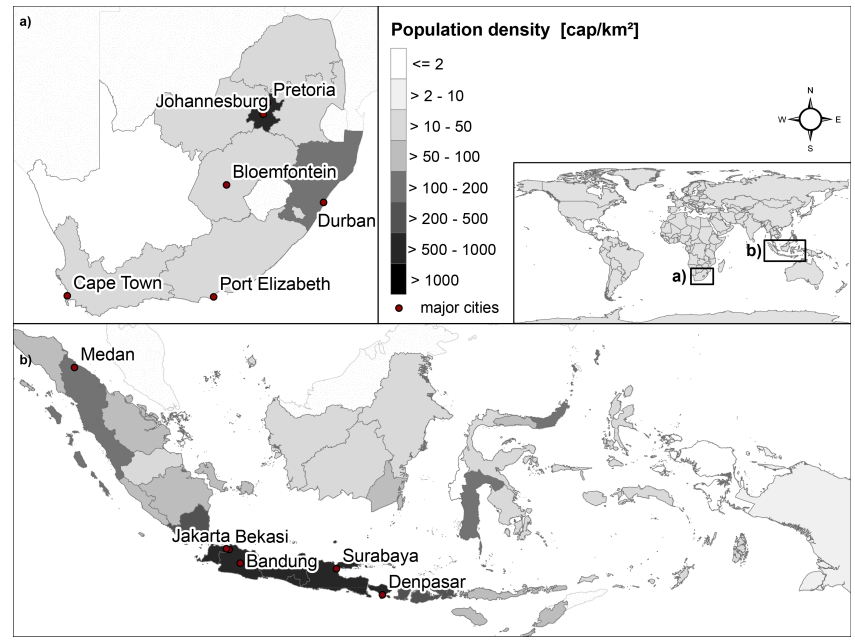

Figure 2. Regional population densities and major cities of the example countries (a) South Africa and (b) Indonesia and their location on the world map.

\subsection{Determinants and indicators to measure the sectoral adequacy of water}

The most important sectors of human water use are the municipal (domestic), agricultural, energy production and industrial sectors (Flörke et al., 2011; WWAP, 2012; Falkenmark, 1997; Chenoweth, 2008). Sectoral attribution is sometimes ambiguous: the definitions of e.g. municipal and domestic water use overlap or are used interchangeably (Chenoweth, 2008; FAO, 2013; Flörke et al., 2011). Some estimations of water use and needs for agriculture include live- stock production (FAO, 2013), while others account for the two sectors separately (Flörke et al., 2011). Furthermore, water needs for energy and industrial production are often added up (Flörke et al., 2011) and are much more dependant on development status and country-specific conditions than other sectors (Chenoweth, 2008; Sullivan, 2002) (see Table 1 for details). For the purpose of the analysis, we distinguish the three sectors - municipal, agricultural (including livestock) and industrial (including energy production) -, as this is the most common and applicable differentiation. An additional important aspect that we take into account is the environment as a distinct water user, as functioning (aquatic) ecosystems and biodiversity are essential for healthy and sustainable living conditions and long-term water security (Smakhtin et al., 2004; Molle et al., 2010). For each of the sectors, specific determinants and water needs are differentiated in order to assess the overall water adequacy. The concept and main sectoral determinants are summarized in Fig. 1.

First, for an assessment of water adequacy, sector-specific water-resource needs have to be identified. Table 1 gives an overview of user-/sector-specific water needs estimated from the literature and converted to annual per capita water needs in $\mathrm{m}^{3}\left(\mathrm{~m}^{3} \mathrm{cap}^{-1} \mathrm{yr}^{-1}\right)$. Rather than the actual current water use, the table gives an overview of what has been identified as (minimum) sectoral needs. As the large differences suggest, estimations of water needs differ in their assumptions, and usually do not take into account external (imported) water. Chenoweth (2008), for example, derives a rather low level of water needs, generalizing the current water use in the Netherlands. It is important to note, however, that imports of water 
through goods produced outside of the country are not taken into account here.

The most detailed analyses of generic, sectoral water requirements are the ones presented by Falkenmark (1997) and Falkenmark and Rockström (2004), which are amongst the most widely used indicators of water scarcity for global analysis. Here, water needs are assessed assuming that all needs are met within country boundaries. Further important accounts of municipal water needs include an analysis by Gleick (1998), who calculates a minimum domestic water requirement of $18 \mathrm{~m}^{3} \mathrm{cap}^{-1} \mathrm{yr}^{-1}$, as well as a report by the Howard and Bartram (2003), where a range of 7.2$36 \mathrm{~m}^{3} \mathrm{cap}^{-1} \mathrm{yr}^{-1}$ is identified. Accounts of generalizable environmental water requirements (EWR) have mainly been put forward by Smakhtin et al. (2004), who derive basinspecific EWR as a fraction of overall runoff. Values range between 20 and $50 \%$ of total available resources. As opposed to assessing the sectoral water requirements, which is the focus of the present analysis, existing models addressing water use focus on current and potential future withdrawal and consumption (Flörke et al., 2013; Lissner et al., 2014a). While these provide estimates of potential future developments, they do not assess whether available resources are sufficient in order to meet needs.

Additional to the availability of water resources in sufficient quantity, quality and access also determine water adequacy. Relatively little water is needed for the municipal sector. Here, access infrastructure, as well as water quality, are often a more important limitation to water adequacy (left part of Fig. 1; Rijsberman, 2006; Sullivan, 2002). Rather than looking at resource availability, access to an improved water source is central to the Millennium Development Goals (MDG), for example (UN, 2012). Water quality aspects are also of utmost importance for the municipal sector, as low quality of drinking water has direct consequences for human health (Howard and Bartram, 2003) and may render water non-potable without prior purification (Finlayson et al., 2012). In their assessment of the main threats to global water security, Vörösmarty et al. (2010b) identify several relevant pollutants with direct negative health effects, including nitrogen, phosphorus, pesticides and mercury, as well as organic matter and high sediment loads. ${ }^{1}$

Water needs of the industrial and energy sectors are diverse (middle left of Fig. 1). Water is eventually needed at some stage of the production process, but quantity, quality and other requirements depend strongly on the specific process (Graedel and van der Voet, 2010; WWAP, 2012). A common denominator is the need for cooling water, which is generally needed in production processes, for which some general requirements can be identified (Morrison et al., 2009). Low water quality can increase costs, as water has to be prepared for use. Especially high quantities of suspended sedi-

\footnotetext{
${ }^{1}$ For details on the background of all indicators of water quality used throughout this paper see Vörösmarty et al. (2010b).
}

ments can damage turbines (Graedel and van der Voet, 2010; Vörösmarty et al., 2010b; Morrison et al., 2009). Higher water temperature may also reduce the availability and usability of water for cooling purposes (Graedel and van der Voet, 2010; Vörösmarty et al., 2010b; Van Vliet et al., 2012). Although low water quality does affect industrial production, it is more often a cause of water pollution itself.

About $70 \%$ of withdrawn water goes towards agricultural production (WWAP, 2012), and overall resource availability is the most critical factor for the adequacy of agricultural water (middle right of Fig. 1). Seasonal variability and short-term shortages may be buffered through water storage (dams), as well as through the availability of irrigation infrastructure. While dams may have negative ecological effects for ecosystems, they can increase human water security, both through water storage for situations of shortages, as well as through potential buffering during flooding events (Vörösmarty et al., 2010b; Finlayson et al., 2012). Agricultural production, in general, may be less dependant on water quality, whilst the sector contributes strongly to water pollution. Quality factors that may reduce yields are mainly related to potential salinisation (Vörösmarty et al., 2010b).

Environmental water requirements (EWRs) refer to the fraction of water, which should remain within aquatic ecosystems to ensure adequate long-term ecosystem health and sustainability (Fig 1, right). Basin-specific EWRs depend on prevailing regional climate conditions and vegetation (Smakhtin et al., 2004). Water pollution is an additional critical determinant of ecosystem health, and multiple sources of human activities affect water quality and pollution levels, threatening biodiversity (Vörösmarty et al., 2010b).

Summarizing the determinants of sectoral water adequacy, Table 2 gives an overview of the proposed indicators for the subsequent analysis. Column 2 specifies the indicator name, as used in the remainder of the paper. Columns 3 and 4 summarize the variables and data sources, which are used to quantify each indicator. The data are also discussed in more detail in the following section (Sect. 2.3).

\subsection{Fuzzy logic approach to measuring water adequacy}

A fuzzy logic approach is developed to translate the sectorspecific determinants into an integrated measure of water adequacy. Fuzzy logic allows converting qualitative or inherently fuzzy concepts into mathematical representations by defining linguistic categories and translating the input values into degrees of membership $\left(\mu_{z i}\right)$. For the process of fuzzification, upper and lower thresholds $\iota_{1}$ and $\iota_{2}$ are defined which determine the degree of membership of values to the respective linguistic categories. Furthermore, the shape of the function (e.g. linear, exponential) determines the degree of membership of each element. The fuzzified variables take continuous values between 0 and 1 , representing the degree of membership to the respective concept (see for details e.g. Lissner et al., 2012; Kropp et al., 2001). For the purpose of 


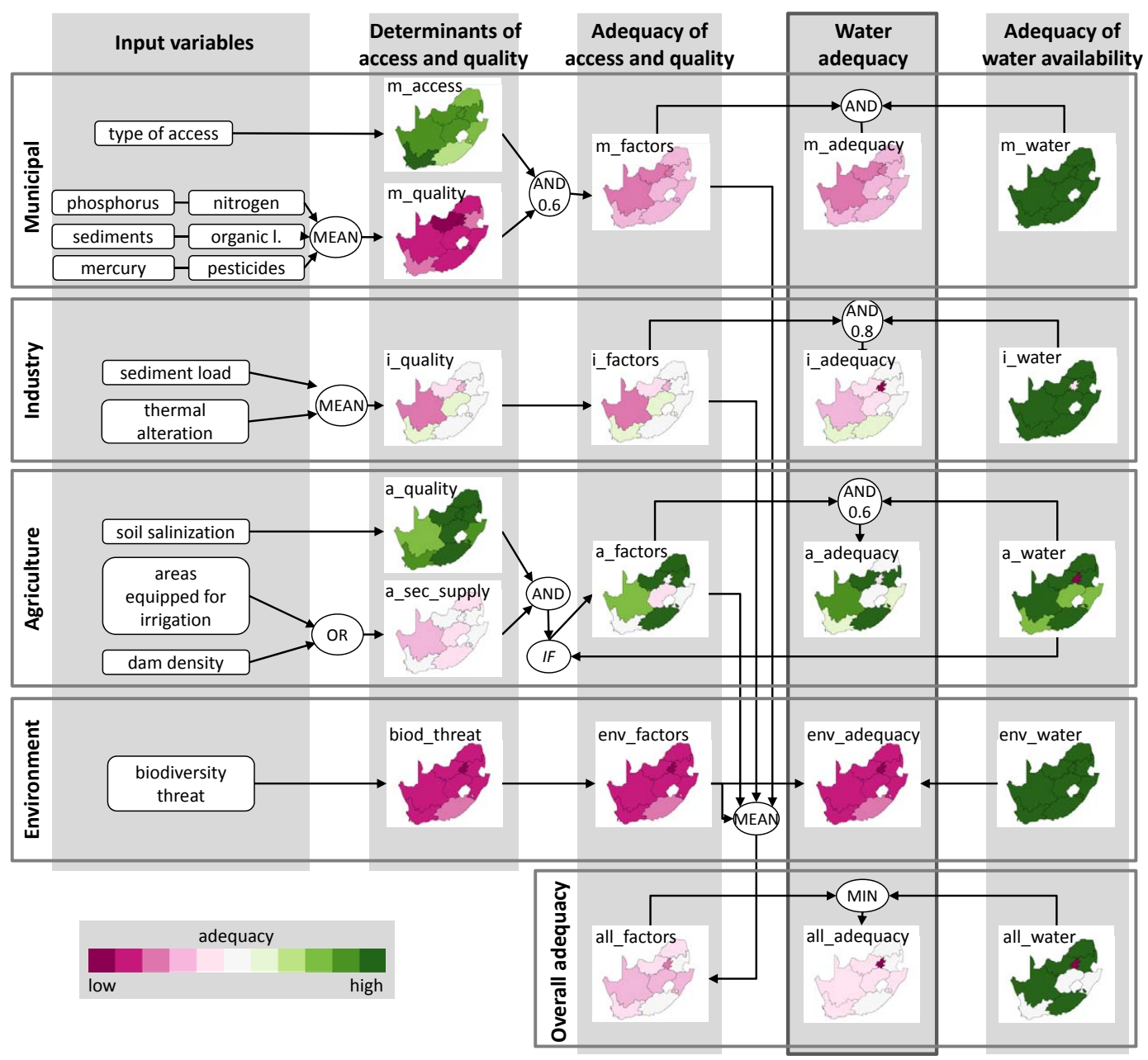

Figure 3. Fuzzy aggregation tree to calculate the adequacy of available water resources. Maps show values for South Africa using water availability data from the HadGEM2-ES model under current conditions (HADbase).

the present analysis, we want to calculate the adequacy of the determinants of water availability, quality and access to derive an integrated measure of water adequacy, where values near 1 indicate highly adequate conditions, and values near 0 indicate inadequacy of the respective component. Equation (1) describes the process of fuzzification for linear membership functions, as used for the purpose of the present analysis.

$\mu_{z i}(\iota)= \begin{cases}0, & \iota \leq \iota_{1} \\ \frac{\iota-\iota_{1}}{\iota_{2}-\iota_{1},} & \iota_{1}<\iota<\iota_{2} \\ 1, & \iota_{2} \leq \iota\end{cases}$

Following the process of fuzzification, the variables can then be aggregated using context-specific decision rules, which allow one to account for relationships between variables. Decision rules should be chosen according to the specific properties of the variables and the analysis. Operators include strict minimum (AND) and maximum (OR) operators, as well as averages such as as harmonic, geometric and arithmetic mean (Mayer et al., 1993). Fuzzy logic further offers the possibility to include the compensating element $\gamma$, which allows using fuzzyAND (Eq. 2) and fuzzyOR operators by taking into account the arithmetic mean to the extent of $\gamma$, with $\gamma$ values near 1 resulting in a strict application of the operator and values near 0 actually calculating the arithmetic mean (Kropp et al., 2001).

$$
\begin{aligned}
& \mu\left(z_{1} \wedge z_{2} \wedge \ldots \wedge z_{n}\right)=\gamma \times \min \left(\mu_{z 1}, \mu_{z 2}, \ldots, \mu_{z n}\right) \\
& +(1-\gamma) \times \frac{1}{N} \sum_{i=1}^{N} \mu_{z i}
\end{aligned}
$$

Figure 3 outlines the aggregation process, showing current values for South Africa. The aggregation for Indonesia follows the same procedure. For each sector, two main aspects are considered: the fuzzified determinants of access and quality (middle column, Fig. 3), as well as the fuzzified adequacy of water availability (right column). We first 
Table 2. Overview of data sources (variables) used to represent the indicators of water adequacy.

\begin{tabular}{|c|c|c|c|}
\hline Sector & Indicator & Variable & Source \\
\hline Municipal & $\begin{array}{l}\text { Municipal water access (m_access) } \\
\text { Municipal water quality (m_quality) }\end{array}$ & $\begin{array}{l}\text { M1: Source of drinking water } \\
\text { M2a: Phosphorus loading } \\
\text { M2b: Nitrogen loading } \\
\text { M2c: Sediment loading } \\
\text { M2d: Organic loading } \\
\text { M2e: Mercury deposition } \\
\text { M2f: Pesticide loading }\end{array}$ & $\begin{array}{l}\text { ICF (2013) } \\
\text { Vörösmarty et al. (2010b) }\end{array}$ \\
\hline Agricultural & $\begin{array}{l}\text { Agricultural water quality (a_quality) } \\
\text { Security of supply (a_sec_supply) }\end{array}$ & $\begin{array}{l}\text { A1: Soil salinisation } \\
\text { A2a: Dam density } \\
\text { A2b: Area equipped for irrigation }\end{array}$ & $\begin{array}{l}\text { Vörösmarty et al. (2010b) } \\
\text { AQUAstat (FAO, 2013) }\end{array}$ \\
\hline Industrial & Industrial water quality (i_quality) & $\begin{array}{l}\text { I1: Sediment loading } \\
\text { I2: Thermal alteration }\end{array}$ & Vörösmarty et al. (2010b) \\
\hline Environmental & $\begin{array}{l}\text { Environmental water quality and } \\
\text { Biodiversity threat (biod_threat) }\end{array}$ & E1: Biodiversity threat & Vörösmarty et al. (2010b) \\
\hline $\begin{array}{l}\text { Water } \\
\text { availability }\end{array}$ & Available water resources (all_water) & $\begin{array}{l}\text { W1: Total runoff } \\
\text { (surface and subsurface) }\end{array}$ & $\begin{array}{l}\text { LPJmL (Bondeau et al., 2007; } \\
\text { Warszawski et al., 2014) }\end{array}$ \\
\hline
\end{tabular}

calculate individual sector adequacy and subsequently aggregate all values to an integrated measure of water adequacy. Each step of fuzzification and aggregation follows a contextspecific reasoning process.

\subsubsection{Fuzzy reasoning process and data preparation}

In order to represent the various factors that influence the adequacy of water, we focus on sources that provide comparable and consistent estimates for both countries. The data and fuzzification process to represent the sectoral determinants are outlined in the following paragraphs and summarized in Table 2. Vörösmarty et al. (2010a) provide a comprehensive global database of water quality indicators for the year 2000, which we use to represent the individual indicators of water quality for each sector. The available data provides estimates of water quality at global scale for various indicators. Where data from this source is used, it was prepared as follows: data are originally provided as values between 0 and 1 , where values near 0 indicate low threat intensity, and values near 1 indicate severe threats to water security. We calculated the mean threat intensity for the administrative regions of the two case study countries and invert these values, so that values near 1 indicate adequate water quality (low pollution threat) and values near 0 indicate low water quality (high pollution threat). Therefore, no further fuzzification is required for these values.

\section{Municipal water adequacy}

In the case of municipal water adequacy, infrastructure to access water resources plays an important role. To measure municipal water access, improved and unimproved water sources are differentiated (Howard and Bartram, 2003; ICF, 2013). The MEASURE Demographic and Health surveys (ICF, 2013) provide access to detailed indicators, aggregated to administrative regions (M1, Table 2). To represent the adequacy of access to drinking water (m_access), we weight the different types of access according to their adequacy (weights adapted from Howard and Bartram (2003), Table 6 ). Water piped onto the premises has a weight of 1 , and access through a well has weight of 0.5 , while all other types of access have a weight of 0.2 . The sum of the weighted access types returns values between 0 and 1 , where values near 1 indicate highly adequate $m \_$access (i.e. a very high proportion of the population with water piped onto premises), whereas values near 0 indicate inadequate $\mathrm{m}_{\text {_access. Also, }}$ water quality plays a prominent role. Contaminated drinking water either renders the water non-usable or threatens human health. Various aspects determine municipal drinking water quality (m_quality) (see Sect. 2.2). The most important contaminants that affect municipal water quality, as identified by Vörösmarty et al. (2010a), are phosphorus loading (M2a), nitrogen loading (M2b), sediment loading (M2c), organic loading (M2d), and mercury deposition (M2e), as well as pesticide loading (M2f).

High-quality water infrastructure (m_access) plays an important role in mitigating potential negative effects of low water quality in the municipal sector ( $\left.m \_q u a l i t y\right)$. For the aggregation of the municipal determinants of access and quality (m_factors), this translates into the fuzzy reasoning process as a fuzzyAND operator, where both aspects have to be sufficiently available for adequacy to be high. However, as highly adequate access infrastructure can reduce contaminants, a $\gamma$ value of 0.6 is introduced, allowing one to compensate to 
some extent (Fig. 3, column 3). While comparatively little water is needed to fulfil municipal water needs (m_water), water availability is nonetheless obviously essential and a strict fuzzyAND is applied to aggregate the overall measure of municipal water adequacy (m_adequacy) to account for this fact (Fig. 3, column 4).

\section{Industrial water adequacy}

The common denominator to assess industrial water adequacy is the availability of cooling water of sufficient quality, which can be represented by the sediment load (I1) as well as water temperature (thermal alteration, I2) (Vörösmarty et al., 2010b). Both the quality (i_quality) as well as sufficient water availability (i_water) determine the adequacy of industrial water resources (i_adequacy). However, low water quality does not completely inhibit cooling-water extraction. We therefore use fuzzyAND with a $\gamma$ value of 0.8 to aggregate the indicators for the overall measure of industrial water adequacy (i_adequacy).

\section{Agricultural water adequacy}

For the agricultural sector as the highest water user, sufficient water availability (a_water) is most important (W1, see also Table 1). Infrastructure to buffer potential shortages can reduce the risk of inadequate water supply. Both the availability of dams as well as irrigation infrastructure can provide such infrastructure. As either of these two indicators may increase water security, these are aggregated using a fuzzyOR. Dam density (A2a) is included in the river threat database (Vörösmarty et al., 2010a) and prepared as described. Similarly, data on areas equipped for irrigation (A2b) is provided in percentage values and is averaged over the administrative regions. Finally, water quality for the agricultural sector (a_quality) is represented by the potential soil salinisation (A1) (Vörösmarty et al., 2010a). Infrastructure to ensure the security of the supply of water for agriculture (a_sec_supply) is especially important in regions where available water resources are close to or below thresholds of water needs. To account for this, we introduce an "if" clause into the analysis: only if water availability is below the threshold of adequacy does supply infrastructure become relevant for the analysis. Where water availability is limited, the security of supply indicator plays an important role. As slight shortages in water availability can be compensated in this way, a $\gamma$ value of 0.6 is introduced to combine adequacy of access and quality (a_factors) with water availability (a_water) for the agricultural sector.

\section{Environmental water adequacy}

EWRs are prioritized in our analysis in the following way: we assume that sufficient water is retained for ecosystems by deducting EWRs from the overall water resources, before assessing water availability for other sectors. Smakhtin et al. (2004) calculate basin-specific EWRs as a percentage of overall runoff, ranging between 20 and $50 \%$ of total available resources. We average these values over the administrative regions of the case study countries and subtract the respective fraction from the overall water available in the respective region. The remaining water is then available for human use in three sectors, while keeping water availability within sustainable environmental boundaries. Environmental water quality is represented by an integrated indicator of biodiversity threat (biod_threat, B1), representing relevant pollution and disturbance factors (Vörösmarty et al., 2010b).

Currently, no projections of the potential future development of the introduced variables are available. Therefore, values for the assessment of current, as well as short-term, future water adequacy are kept constant for aspects of access and quality. Projected changes derive from the variables water availability, as well as population.

\subsubsection{Scenarios of water availability and population}

Water availability for the purpose of the analysis describes the total internal renewable water resource, as required for the assessment of water scarcity according to Falkenmark (1997) and Falkenmark and Rockström (2004). To measure water availability and calculate future scenarios of climate change impacts, we use output from the Lund-PotsdamJena-managed land (LPJmL) model, a dynamic global vegetation and water balance model (Bondeau et al., 2007). Specifically, we use the mean total surface and subsurface runoff per grid cell. We make use of publicly available results generated within the framework of the Inter-Sectoral Impact Model Intercomparison Project (ISI-MIP; Warszawski et al., 2014).

Calculations are based on two representative concentration pathways (RCP) as forcings for the two employed global climate models (GCMs): HadGEM2-ES and GFDLESM2M (van Vuuren et al., 2011). We calculate mean annual water availability for a baseline (1981-2010) and a short term (2011-2040) scenario, based on the two GCMs, using RCP2.6 and RCP8.5. The GCM-RCP combinations are further referred to as: HADbase, HAD2.6, HAD8.5, GDFLbase, GDFL2.6 and GDFL8.5. Similar to the preparation of waterquality data, we calculated values for the administrative regions, summing up the cell values to derive yearly values of water availability per administrative unit. To assess per capita availability, we rely on regionalized population projections from the National Statistical Offices for the case study regions and divide the total available water resource by the population - Indonesia: BAPPENAS (2005), South Africa: van Aardt $(2007)^{2}$. In both countries, population is expected to increase in the coming decades. Projections of water resources indicate marginal change in overall water resource

\footnotetext{
${ }^{2}$ Available subnational projections for South Africa exist up to the year 2021; we applied the national available growth rates to the projected data for 2021 to derive values for 2025
} 
availability for both countries, with larger differences between the two GCMs than between representative concentration pathways (RCPs) and the time slices. All input data for the administrative regions is published in the Supplement at figshare (Lissner et al., 2014b).

In order to assess the adequacy of available water resources using fuzzy values, (m_water, i_water, a_water and all_water), we use the rounded lower and upper ranges, as identified in Table 1 (column: "Thresholds"), for the process of fuzzification. Here, the lower identified threshold refers to the minimum water need identified in the literature and the upper threshold denotes a situation of adequacy. To derive individual values of adequacy for each sector, we initially assume that the total water resource would be available to meet the needs of the single sectors. To then assess the overall adequacy of water availability across all sectors, the needs of all sectors are summed to assess the cumulative adequacy of overall water resources (all_water).

To finally derive an integrated indicator of overall water adequacy (all_adequacy), sectoral quality and access aspects are combined with the overall water needs across sectors. For the purpose of exemplifying the approach, we use a mean operator to aggregate all sectoral determinants of access and quality (all_factors), but combine these indicators with the overall water availability (all_water) using a strict "min" operator, reflecting the fact that sufficient resource availability is a prerequisite.

\section{Results}

The overall adequacy of water is a function of all factors that affect the quantity, quality and access to water by relevant sectors. Besides outlining the aggregation procedure, Fig. 3 also presents results in the form of maps, representing the fuzzified and aggregated values for South Africa for each analysis step for current conditions of water availability (GDFLbase). The analysis is conducted calculating the degree of membership to the linguistic category "conditions are adequate", which translates into results of water adequacy ranging from very high $(0.8-1)$, high $(0.6-0.8)$, intermediate $(0.4-0.6)$, low $(0.2-0.4)$ to very low $(0-0.2)$. As generally visible, access factors critically determine the resulting values of water adequacy: while the adequacy of available water resources is (very) high in terms of quantity for most sectors, access and quality have a strong influence on the results.

Water quality plays an especially important role for the adequacy of municipal water resources in South Africa. Although the adequacy of access (m_access) is high to very high, municipal water quality (m_quality) is (very) low and leads to inadequate municipal adequacy of access and quality ( $m$ _factors). For the industrial sector, available resources suffice to meet needs, but alterations of quality reduce its adequacy in all regions. Due to the high agricultural water needs (a_water), limitations are faced in some regions

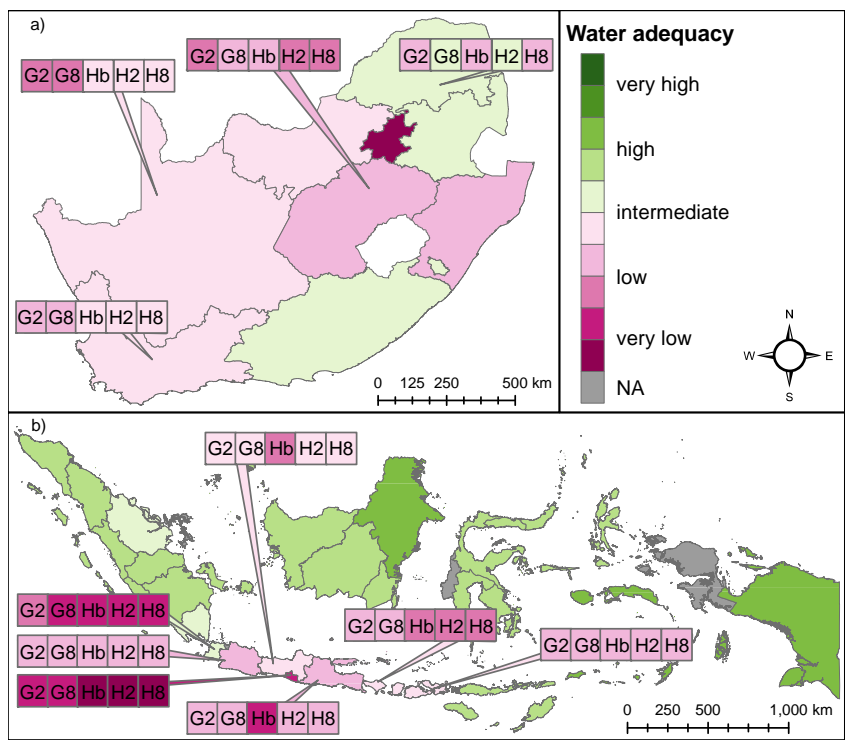

Figure 4. The maps show the integrated measure of water adequacy under current conditions (GDFLbase) for (a) South Africa and (b) Indonesia. Coloured boxes show changes in water adequacy where these occur, differentiating the models and RCPs. G2: GDFL2.6, G8: GDFL8.5, Hb: HADbase, H2: HAD2.6 and H8: HAD8.5.

of South Africa. Both the areas equipped for irrigation as well as the dam density are rather low, thus the security of supply is often insufficient to buffer potential shortages. Nonetheless, agricultural adequacy (a_adequacy) is intermediate to high all over South Africa. The integrated indicator depicting a regional biodiversity threat shows that waterquality pressure on the environment is high, negatively affecting the environmental water adequacy (env_adequacy). The mean adequacy of determinants of access and quality as a combination of all sectoral determinants (all_factors) is low to intermediate. The sum of sectoral water requirements (all_water) shows limitations in resource availability, especially in densely populated areas, hinting at potential competition between sectors. The overall result depicting water adequacy (all_adequacy) is an aggregate of all input factors and cumulative water requirements of all sectors, mainly reflecting the limitations in access and quality factors across regions.

Figure 4 shows the integrated water adequacy (all_adequacy) for South Africa and Indonesia for current conditions, as well as future changes where applicable. In both countries, regions of lowest adequacy are those with the highest population density (depicted in Fig. 2). Projected changes in water availability do not affect the overall adequacy of water for human use in most regions, as quality and access play such an important role. However, changes are apparent in some regions. Here, differences between the two applied models also become visible. Population density plays a crucial role in determining the 
adequacy of water availability (all_water). A large number of users may lead to overall scarcity, either due to resource limitations or quality restrictions. In the example countries, regions with high population density are currently close to the thresholds of water scarcity and population growth is likely to aggravate the situation. The projections of future water availability only project marginal changes in overall water resource availability in both countries, and, in several regions, changes may lead to increases in water resources. However, due to an increase in population, especially in already densely populated areas, per capita availability declines, leading to potential water scarcity.

In South Africa, mean overall adequacy (all_adequacy) is intermediate to low (GDFLbase: 0.41, HADbase: 0.4) and the highest values of adequacy also remain at intermediate levels with values between 0.51 and 0.55 in the regions of the Eastern Cape, Mpumalanga and Limpopo. The water adequacy is most severely limited in Gauteng, with a very low adequacy of 0 . Although, generally, resource availability under the current climate is very adequate in the regions of South Africa, municipal and industrial water quality are low to very low in many areas.

In Indonesia, water resources are generally abundant, but the metropolitan region of Jakarta faces some water limitation, and projections of water availability show further reductions in the region. Although overall water availability is projected to increase in most regions, population growth in already populous areas of the country is also projected to increase significantly, keeping constant or diminishing per capita water availability.

The island of Java, for example, is home to the largest cities and shows the lowest values of water adequacy and a decrease in adequacy over the coming decades. Mean adequacy under current conditions in Indonesia is intermediate, with lowest values in the densely populated regions of Bali with intermediate to low water adequacy. Similarly, the regions of Central, East and West Java, as well as Yogyakarta, display low to very low values. Where adequacy is low under current conditions in Indonesia, further changes are projected, leading to additional reductions in water adequacy. Conditions are best in Maluku Islands, East Kalimantan and Papua, with high values across models and scenarios. Generally, access to an improved water source (m_access) is low to intermediate, leading to an overall reduced adequacy (m_adequacy). Water quality in Indonesia for all users is intermediate to high and water availability is high, except for the densely populated regions. As measures to increase the security of the supply of water for irrigation purposes are relevant mainly where water shortages are to be expected, agricultural adequacy (a_adequacy) is high, despite a lack of irrigation equipment and low dam density in many regions. The security of supply indicators performs best in those regions, where water availability is below the scarcity threshold, allowing one to buffer potential shortages in water resources.
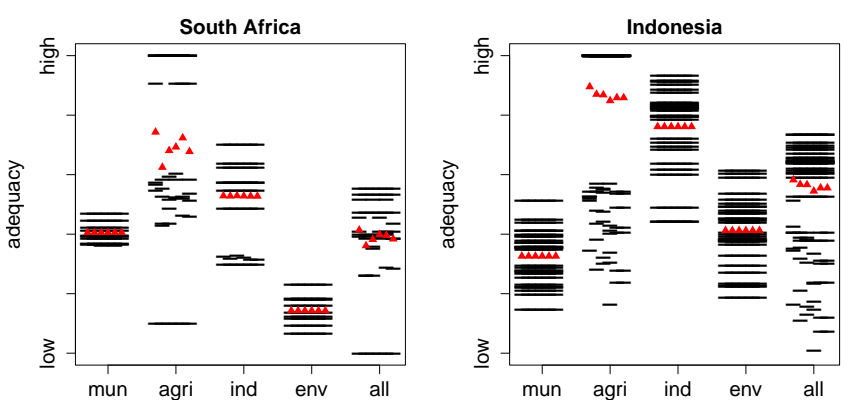

Figure 5. Sectoral water adequacy in South Africa (left) and Indonesia (right), showing results for the individual sectors $\quad$ (mun = municipal, agri $=$ agricultural, $\quad$ ind $=$ industrial, env =environmental, all=overall). Black lines show results for the individual municipalities, and red triangles show the country average for results across models and RCPs from left to right: GDFLbase, GDFL2.6, GDFL8.5, HADbase, HAD2.6, HAD8.5.

\subsection{Sectoral priorities of water adequacy}

While an overall aggregate indicator of water adequacy gives important information on the overall situation of water security, a sectoral differentiation allows prioritizing especially stressed sectors in order to most efficiently improve water adequacy. Comparing the sectoral adequacy, it is apparent that the municipal, as well as environmental, water adequacy are lowest, in both South Africa and Indonesia, also showing the lowest spread between regions (Fig. 5). In Indonesia, municipal water adequacy is lowest in rural regions, where especially the access to improved water sources is limited. In several regions, environmental water quality dominates the result. In the most densely populated regions of Bali, as well as East and West Java, the overall water availability proves to be a limitation under future conditions.

Agricultural water adequacy shows the highest spread across regions in both countries. While the mean adequacy is intermediate to high in both countries, some regions are severely water constrained. When looking at the overall adequacy of the three different sectors (municipal, industrial and agricultural), the analysis shows that, for the municipal and industrial sectors, the main impediments are water quality and access factors, rather than the availability of water resources. This also holds for short-term future scenarios. In the case of agricultural water resources, however, the availability of sufficient irrigation water plays a role in some regions of the case study countries.

Identifying the most relevant sectors and factors for each region in determining the adequacy of water resources provides important information to improve the quality of water resources and access in an efficient way. Figure 6 shows which sectors most severely constrain water adequacy in each region. Where this factor changes over time, this is indicated by a box in the respective colour. In the case of South Africa, environmental water adequacy is a severe constraint 


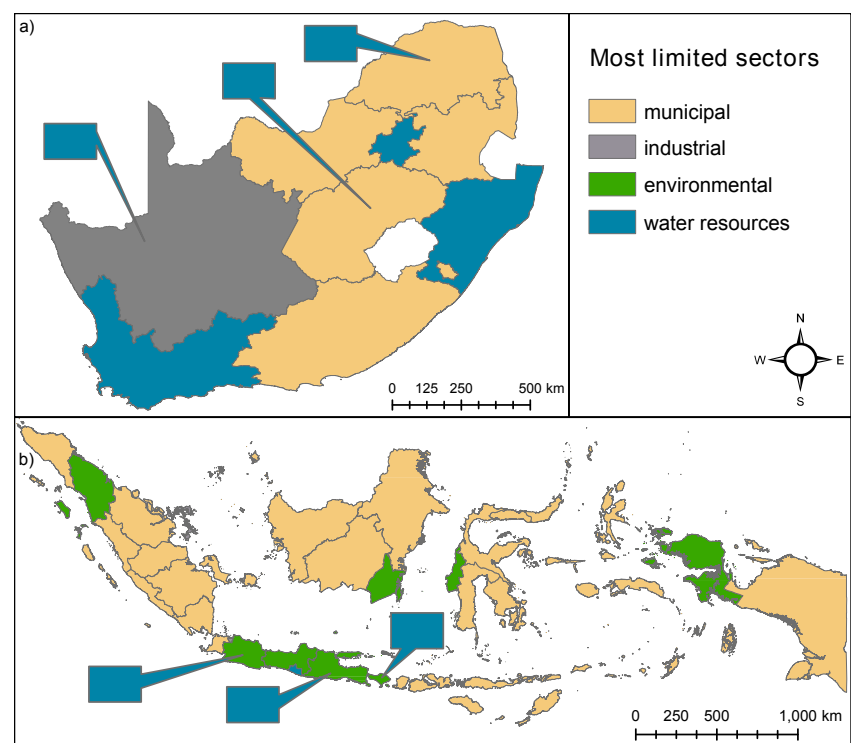

Figure 6. Overview of the most limited sectoral adequacy for the regions of (a) South Africa and (b) Indonesia. Where changes occur across scenarios, these are indicated by a box in the respective colour. Note that the sectoral limitations shown for South Africa are the second-most important after the environmental sector.

for all regions and has the strongest influence on the overall result. The map therefore shows the second-most limiting factor. Environmental water conditions for the regions of Indonesia are also often low and follow as second-most limiting factors for all regions.

In the case of South Africa, the results in the majority of regions are dominated by limitations in municipal water adequacy when environmental constraints are not taken into account, except for those of the region of Gauteng, in which water resources limit the results. However, here, municipal water quality plays a much more important role than access. Similar to the findings in Indonesia, high population density (see Fig. 2) leads to limitations in water resources availability (all_water) in South Africa, especially under future conditions. The regions of the Western Cape and KwaZulu-Natal are water limited in all scenarios, and water limitations are expected in Northern Cape, Free State and Limpopo in the future. The largest province of Northern Cape is a sparsely populated region in which mining is a predominant activity. Here, the industrial water quality is the most decisive factor for adequacy under current conditions.

\section{Discussion}

Our results highlight that sector-specific water needs are diverse and that several distinct factors determine whether the quality, quantity and access to resources are adequate. Calculating water adequacy for two case study countries, the present work exemplifies how such an integrated approach can be applied. Changing resource availability, as well as population increases, has an impact on the patterns of water adequacy. For effective and informed decision-making, it is essential to provide detailed and applicable information on the sectoral differences that affect the adequacy of water resources.

The results of the analysis clearly show that infrastructure (municipal access and security of supply) and quality aspects play an important role to determine water adequacy. Although insufficient water resources, also over the course of the next decades, have an impact in some regions, the distribution of population often plays an important role, as densely populated places face more severe water scarcity.

In some of the analysis regions, agricultural water is already limited. In Indonesia, for example, most agricultural production currently takes place on the densely populated island of Java. Here, water resources are already limited and population growth in this region may aggravate the problem. Reduced water availability in the future may affect domestic food security if available water resources become insufficient in relevant growth phases and supply infrastructure is insufficient to meet additional demand. Even today, Indonesia is a net importer of food, and malnutrition and stunting among children is present (WFP, 2012). With increasing development and higher demand lifestyles, the water intensity of food-consumption patterns may increase, further exacerbating the problem (Pradhan et al., 2013).

Our findings show that, in Indonesia, the security of a supply indicator is usually adequate in regions where water availability is below the threshold, implying that awareness of shortages is present and potential scarcity can be buffered to some extent. Contrary to this, in South Africa, buffering infrastructure in the from of irrigation equipment and dams is inadequate in the whole country, leading to low agricultural adequacy in some regions. Due to the current low per capita water use $\left(284 \mathrm{~m}^{3} \mathrm{cap}^{-1} \mathrm{yr}^{-1} ; \mathrm{FAO}, 2005\right)$, water demand remains below available supply, therefore the overall water availability is currently not the main limitation to water access; rather, inadequate supply infrastructure and lacking quality are an important impediment to adequate water (IRIN, 2009; Muller et al., 2009), which is also visible in our results. Although water is scarce in some regions, South Africa is currently a net food exporter. However, with a trend towards more water-intensive lifestyles, water demand is expected to overtake supply in the coming years, which may lead to competitions between sectors.

Currently, water use in both example countries is below the minimum requirement identified in the literature Table 1, Indonesia: $531 \mathrm{~m}^{3} \mathrm{cap}^{-1} \mathrm{yr}^{-1}$ (FAO, 2011); South Africa: see above. Increasing development may lead to additional pressures here as lifestyles adjust to prevailing patterns in highly developed countries and water use increases. Improved access to water resources, which, for example, is urgently needed in many regions of the case study countries, has been shown to increase water consumption, as more 
water is used e.g for hygiene purposes, an important improvement to heath status (Larson et al., 2006). Our results show that water is already a limiting factor in some densely populated regions today. Here, growing water demand would indeed be critical. Especially in regions where high population growth and high development is expected, integrated water management schemes may therefore become increasingly important. The projections of climate impacts on water resources in the present analysis focus on a short-term future scenario until 2030. Projected changes in water resource availability are not pronounced on this timescale, but changes in population are the main driver of reductions in per capita water availability.

Limitations in water quality play a very decisive role in both countries and in all sectors. Particularly the environmental water adequacy proves to be one of the most limiting factors for water security/adequacy, due to increasing threats to biodiversity from high pollution levels. Even when prioritizing environmental water needs, as has been done in the present approach by allocating environmental water needs before other sectors, water quality threatens environmental water sustainability. Where access to drinking water is not provided through improved sources, high pollution levels may also have direct health implications. Additionally, lowquality water for agriculture may also lead to reduced yields or health effects due to contaminated foods (Toze, 2006). Sustainable adaptation and development in the water sector should concentrate on improving water infrastructure and on improving the quality of accessible water in many regions. Improving infrastructure can also reduce the susceptibility to impacts of climate extremes, as contamination and disruption of water infrastructure then becomes less likely.

The presented approach was developed to be applicable in developing countries, enabling comparability between regions. It provides an overview of the main determinants of water adequacy and is applied in a first exemplary approach, using comparable data for two case study countries. In its present form, the approach has some limitations. By using global data sets, for example, comparable results between countries are produced. However, regionally collected data may reflect regional to local conditions more accurately. To reconcile the goal of comparable analyses with more detailed accounts of regional specificities, further analyses of local conditions could provide additional details, providing a more comprehensive picture. Regional to local implementations of the methodology could also take into account local characteristics, such as water-intensive industries and energy production types, providing further detail on locally specific limitations to sectoral water adequacy. This would also allow us to include the knowledge of regional experts through participatory approaches. The sectoral allocation of water needs currently addresses potential water requirements, rather than water use or withdrawal. Consequently, water used by one sector is assumed to be unavailable for other purposes. Including a more process-based view of water use, also ac- counting for the potential for successive use water resources between sectors would provide an additional improvement of the approach.

Additionally, variations in water requirements could be taken into account in a localized application of the approach. This could include differences according to the specific regional distribution of production patterns, for example, as well as changes resulting from expected future development. Moreover, seasonal variations in water availability play an important role at the local and regional scales, but have not been included in the present application. Particularly for agricultural production, seasonal variations in precipitation and water availability play an important role in determining water adequacy. In order to be applicable as a tool for locally specific decisions on water management, further refinement of the specific regional priorities would be needed. For the present implementation, we chose to rely on generic and generally valid assumptions on water requirements. Detailed assessment of the prevailing local requirements would be an important improvement of the approach. Finally, the forecasting capacity of the results, with regard to future developments, is limited, as the quality and infrastructural components could not be calculated with scenario values in a comparable way, as data were unavailable at present.

The fact that infrastructure, access and quality are often more important than water availability itself in determining adequate water availability, especially in developing countries, is widely recognized (Rijsberman, 2006). However, quantifications to identify the most pressing factors on a subregional scale have, so far, been lacking. The presented approach outlines a novel way of providing comparable results across regions to identify which aspects of water supply need to be improved most urgently. The approach can point towards adaptation strategies that allow prioritizing between different development goals and choosing strategies, which most efficiently improve water availability. The approach allows testing different allocation patterns for different water sectors and can show at which point overall water adequacy could be most efficiently increased by adjusting single factors of the analysis.

As water resources become scarce, either due to increasing population and demand, or through a reduction in resource availability, competition between different sectors to have access to sufficient water resource may arise. The present approach allows one to identify needs of different users and make visible which aspects are important in different regions. By taking into account sector-specific needs, the approach can provide management-relevant information for decisionmakers. It also allows the identification of potential trade-offs and competitions between sectors. 


\section{Conclusions}

This paper presents an integrated approach to determine how important sectors are adequately supplied with water. The applied fuzzy logic algorithm allows the identification of regions with inadequate water supply in a comparable way. The approach also allows the identification of the factors and sectors that are most important in a regional context, contributing to decision-making processes for sustainable development and integrated climate change adaptation. It is clear that water scarcity is essentially human-made, and population density, infrastructure and associated pollution determine whether available water is sufficient and in adequate form to be used. Continued population growth, coupled with increases in per capita water consumption, are important determinants of reductions in water adequacy. In the current short-term future scenario, climate change has little influence on the reduction in water availability, although, towards the end of the century, this may pose additional pressure on water resources. It is essential to increase knowledge of processes that determine adequate water availability, as access to sufficient clean water is the most critical of human needs. Thus, improving access to water has high priority, especially in developing countries in which development and human wellbeing are often severely restricted by a lack of water access. Applicable approaches, which combine a range of determinants of water adequacy and allow one to prioritize interventions, are urgently needed to advance sustainable development. The presented approach is an important contribution to improve knowledge and cope with the multiple challenges that the water sector faces.

Acknowledgements. The work has been developed within a project funded by the German Federal Ministry of the Environment, Nature Conservation and Nuclear Safety, specifically through the International Climate Intiative (ICI). We wish to thank the three reviewers for their important comments, which have improved the final version of the manuscript.

Edited by: D. Mazvimavi

\section{References}

Alcamo, J., Döll, P., Henrichs, T., Kaspar, F., Lehner, B., Rösch, T., and Siebert, S.: Global estimates of water withdrawals and availability under current and future "businessas- usual" conditions, Hydrolog. Sci. J., 48, 339-348, doi:10.1623/hysj.48.3.339.45278, 2003.

Almeida, G., Vieira, J., Marques, A. S., Kiperstok, A., and Cardoso, A.: Estimating the potential water reuse based on fuzzy reasoning., J. Environ. Manage., 128, 883-892, doi:10.1016/j.jenvman.2013.06.048, 2013.

BAPPENAS: Indonesia Population Projection 2000-2025, http: //www.datastatistik-indonesia.com/proyeksi/index.php (last access: March 2014), 2005.
Bates, B., Kundzewicz, Z., Wu, S., and Palutikof, J.: Climate change and water, Technical Paper of the Intergovernmental Panel on Climate Change, IPCC Secretariat, Geneva, 2008.

Bondeau, A., Smith, P. C., Zaehle, S., Schaphoff, S., Lucht, W., Cramer, W., Gerten, D., Lotze-Campen, H., Müller, C., Reichstein, M., and Smith, B.: Modelling the role of agriculture for the 20th century global terrestrial carbon balance, Glob. Change Biol., 13, 679-706, doi:10.1111/j.13652486.2006.01305.x, 2007.

Brown, A. and Matlock, M. D.: A Review of Water Scarcity Indices and Methodologies, Tech. rep., University of Arkansas, The Sustainability Consortium, Tempe, Arizona USA, 2011.

Chenoweth, J.: Minimum water requirement for social and economic development, Desalination, 229, 245-256, doi:10.1016/j.desal.2007.09.011, 2008.

Collins, M., Knutti, R., Arblaster, J., Dufresne, J.-L., Fichefet, T., Friedlingstein, P., Gao, X., Gutowski, W., Johns, T., Krinner, G., Shongwe, M., Tebaldi, C., Weaver, A., and Wehner, M.: Long-term Climate Change: Projections, Commitments and Irreversibility, in: Climate Change 2013: The Physical Science Basis. Contribution of Working Group I to the Fifth Assessment Report of the Intergovernmental Panel on Climate Change, edited by Stocker, T., Qin, D., Plattner, G.-K., Tignor, M., Allen, S., Boschung, J., Nauels, A., Xia, Y., Bex, V., and Midgley, P., chap. 12, Cambridge University Press, Cambridge, UK and New York, USA, 2013.

Eriyagama, N., Smakhtin, V., and Gamage, N.: Mapping Drought Patterns and Impacts: A Global Perspective, Tech. rep., IWMI Research Report 133, International Water Management Institute, Colombo, Sri Lanka, 2009.

Falkenmark, M.: Meeting water requirements of an expanding world population, Philos. T. Roy. Soc. B., 352, 929-936, doi:10.1098/rstb.1997.0072, 1997.

Falkenmark, M. and Rockström, J.: Balancing water for humans and nature. The new approach in ecohydrology, Earthscan, London, UK, 2004.

FAO: Irrigation in Africa in figures - South Africa, Tech. rep., AQUASTAT/FAO, ftp://ftp.fao.org/agl/aglw/docs/wr29_eng.pdf (last access: March 2014), 2005.

FAO: Irrigation in Southern and Eastern Asia in figures - Indonesia, Tech. rep., AQUASTAT/FAO, http://www.fao.org/docrep/ 016/i2809e/i2809e.pdf (last access: March 2014), 2011.

FAO: AQUASTAT database, Food and Agriculture Organization of the United Nations (FAO), http://www.fao.org/nr/water/aquastat/ main/index.stm, last access: October 2013.

Finlayson, B. L., Barnett, J., Wei, T., Webber, M., Li, M., Wang, M. Y., Chen, J., Xu, H., and Chen, Z.: The drivers of risk to water security in Shanghai, Reg. Environ. Change, 13, 329-340, doi:10.1007/s10113-012-0334-1, 2012.

Flörke, M., Bärlund, I., and Kynast, E.: Will climate change affect the electricity production sector? A European study, J. Water Clim. Change, 3, 44, doi:10.2166/wcc.2012.066, 2011.

Flörke, M., Kynast, E., Bärlund, I., Eisner, S., Wimmer, F., and Alcamo, J.: Domestic and industrial water uses of the past 60 years as a mirror of socio-economic development: A global simulation study, Glob. Environ. Change, 23, 144-156, doi:10.1016/j.gloenvcha.2012.10.018, 2013.

Gharibi, H., Mahvi, A. H., Nabizadeh, R., Arabalibeik, H., Yunesian, M., and Sowlat, M. H.: A novel approach in water quality 
assessment based on fuzzy logic., J. Environ. Manage., 112, 8795, doi:10.1016/j.jenvman.2012.07.007, 2012.

Gleick, P.: The human right to water, Water Policy, 1, 487-503, doi:10.1016/S1366-7017(99)00008-2, 1998.

Graedel, T. and van der Voet, E.: Linkages of Sustainability, The MIT Press, Cambridge, Massachusetts USA, 2010.

Hoekstra, A. Y. and Chapagain, A. K.: Water footprints of nations: Water use by people as a function of their consumption pattern, Int. Ser. Prog. Wat. Res., 21, 35-48, doi:10.1007/s11269-0069039-x, 2006.

Howard, G. and Bartram, J.: Domestic Water Quantity, Service Level and Health, Tech. rep., World Health Organization, Geneva, Switzerland, 2003.

ICF: MEASURE DHS STATcompiler, ICF International, http:// www.statcompiler.com/, last access: October 2013.

IRIN: SOUTH AFRICA: Clock ticks towards water scarcity, http://www.irinnews.org/report/84517/ south-africa-clock-ticks-towards-water-scarcity (last access: March 2014), 2009.

Kirtman, B., Power, S., Adedoyin, J., Boer, G., Bojariu, R., Camilloni, I., Doblas-Reyes, F., Fiore, A., Kimoto, M., Meehl, G., Prather, M., Sarr, A., Schär, C., Sutton, R., van Oldenborgh, G., Vecchi, G., and Wang, H.: Near-term Climate Change: Projections and Predictability, in: Climate Change 2013: The Physical Science Basis. Contribution of Working Group I to the Fifth Assessment Report of the Intergovernmental Panel on Climate Change, edited by: Stocker, T., Qin, D., Plattner, G.-K., Tignor, M., Allen, S., Boschung, J., Nauels, A., Xia, Y., Bex, V., and Midgley, P., chap. 11, Cambridge University Press, Cambridge, UK and New York, USA, 2013.

Kropp, J., Lüdeke, M. K. B., Reusswig, F., and Change, G.: Global Analysis and Distribution of Unbalanced Urbanization Processes: The FAVELA Syndrome, GAIA, 10, 109-120, 2001.

Larson, B., Minten, B., and Razafindralambo, R.: Unravelling the linkages between the millennium development goals for poverty, education, access to water and household water use in developing countries: Evidence from Madagascar, J. Dev. Stud., 42, 22-40, doi:10.1080/00220380500356258, 2006.

Lissner, T. K., Holsten, A., Walther, C., and Kropp, J. P.: Towards sectoral and standardised vulnerability assessments: the example of heatwave impacts on human health, Climatic Change, 112, 687-708, doi:10.1007/s10584-011-0231-5, 2012.

Lissner, T. K., Sullivan, C. A., Reusser, D. E., and Kropp, J. P.: Integrated assessments of water scarcity: knowns, unknowns and ways forward, in: The global water system in the anthropocene (in press), edited by: Bogardi, J. J., Bhaduri, A., Leentvaar, J., and Marx, S., Springer, 2014a.

Lissner, T. K., Sullivan, C. A., Reusser, D. E., and Kropp, J. P.: Supplementary Material: Determining regional limits and sectoral constraints for water use considering climate change, available at: figshare, doi:10.6084/m9.figshare.1150217, 2014b.

Mayer, A., Mechler, B., Schlindwein, A., and Wolke, R.: Fuzzy Logic, Addison-Wesley, Bonn, Germany, 1993.

Molle, F., Wester, P., and Hirsch, P.: River basin closure: Processes, implications and responses, Agricultural Water Management, 97, 569-577, doi:10.1016/j.agwat.2009.01.004, 2010.

Morrison, J., Morikawa, M., Murphy, M., and Schulte, P.: Water Scarcity \& Climate Change : Growing Risks for Businesses \& Investors, Tech. rep., Ceres/Pacific Institute, Boston, USA, 2009.
Muller, M., Schreiner, B., Smith, L., Koppen, B. V., Sally, H., Aliber, M., Cousins, B., Tapela, B., Merwe-botha, M. V. D., Karar, E., and Pietersen, K.: Water security in South Africa, Tech. Rep. 12, Development Bank of Southern Africa (DBSA), Midrand, South Africa, 2009.

Pradhan, P., Reusser, D. E., and Kropp, J. P.: Embodied Greenhouse Gas Emissions in Diets, PLoS ONE, 8, e62228, doi:10.1371/journal.pone.0062228, 2013.

Rijsberman, F. R.: Water scarcity: Fact or fiction?, Agr. Water Manage., 80, 5-22, doi:10.1016/j.agwat.2005.07.001, 2006.

Shuval, H.: Approaches to Resolving the Water Conflicts Between Israel and her Neighbors - a Regional Water-for-Peace Plan, Water Int., 17, 133-143, doi:10.1080/02508069208686133, 1992.

Smakhtin, V., Revenga, C., and Döll, P.: A pilot global assessment of environmental water requirements and scarcity, Water Intern., 29, 307-317, doi:10.1080/02508060408691785, 2004.

Sullivan, C. A.: Calculating a Water Poverty Index, World Dev., 30, 1195-1210, doi:10.1016/S0305-750X(02)00035-9, 2002.

Sullivan, C. and Meigh, J.: Targeting attention on local vulnerabilities using an integrated index approach: the example of the climate vulnerability index, Water Sci. Technol., 51, 69-78, 2005.

Toze, S.: Reuse of effluent water?benefits and risks, Agr. Water Manage., 80, 147-159, doi:10.1016/j.agwat.2005.07.010, 2006.

UN: The Millennium Development Goals Report 2012, United Nations, New York, USA, 2012.

UNDP: International Human Development Indicators, http://hdr. undp.org/en/statistics/ (last access: July 2013).

van Aardt, C.: Population and Household Projections for South Africa by Province and Population Group, 2001-2021, Tech Rep. May, Bureau of Market Research, University of South Africa (UNISA), 2007.

van Vliet, M. T. H., Yearsley, J. R., Ludwig, F., Vögele, S., Lettenmaier, D. P., and Kabat, P.: Vulnerability of US and European electricity supply to climate change, Nat. Clim. Change, 2, 676681, doi:10.1038/nclimate1546, 2012.

van Vuuren, D. P., Edmonds, J., Kainuma, M., Riahi, K., Thomson, A., Hibbard, K., Hurtt, G. C., Kram, T., Krey, V., Lamarque, J.F., Masui, T., Meinshausen, M., Nakicenovic, N., Smith, S. J., and Rose, S. K.: The representative concentration pathways: an overview, Clim. Change, 109, 5-31, doi:10.1007/s10584-0110148-z, 2011.

Vörösmarty, C. J., McIntyre, P. B., Gessner, M. O., Dudgeon, D., Prusevich, A., Green, P., Glidden, S., Bunn, S. E., Sullivan, C. A., Liermann, C. R., and Davies, P. M.: Global threats to human water security and river biodiversity, Nature, 467, 555-561, doi:10.1038/nature09440, 2010a.

Vörösmarty, C. J., McIntyre, P. B., Gessner, M. O., Dudgeon, D., Prusevich, A., Green, P., Glidden, S., Bunn, S. E., Sullivan, C. a., Liermann, C. R., and Davies, P. M.: SUPPLEMENTARY INFORMATION: Global threats to human water security and river biodiversity, Nature, 467, 555-561, doi:10.1038/nature09440, 2010b.

Warszawski, L., Frieler, K., Huber, V., Piontek, F., Serdeczny, O., and Schewe, J.: The Inter-Sectoral Impact Model Intercomparison Project (ISI-MIP): project framework., P. Natl. Acad. Sci. USA, 111, 3228-3232, doi:10.1073/pnas.1312330110, 2014.

WFP: World Food Programme - Indonesia, http://www.wfp.org/ countries/indonesia/food-security (last access: October 2013), 2012. 
WHO/UNICEF: Joint Monitoring Programme for Water Supply and Sanitation, Global water supply and sanitation assessment 2000 Report, Tech. rep., World Health Organization and United Nations Children's Fund Publications, Washington, USA, 2000.
WWAP: The United Nations World Water Development Report 4: Managing Water under Uncertainty and Risk, WWAP (World Water Assessment Programme) UNESCO, Paris, France, 2012. 